\title{
Can the Czech Road Tax be considered a Tax on Externalities?
}

\author{
Petr David *
}

\begin{abstract}
:
The transport sector is one of the important components of economic systems. Besides positive effects, it is also a source of external costs transferred to other entities. Through the evaluation of current settings of the tax base and parameters of the road tax rate progressivity it was ascertained that this tax fails to directly or indirectly reflect the external costs of transport. It is through a relatively simple adjustment of the existing road tax rates that indirect reflection of certain items of the road transport external costs may be achieved. Firstly, changes must be made in the definition of the road tax base so as to contain emissions or other parameters of externalities; subsequently, the direct reflection of the road transport external costs in the tax may be achieved.
\end{abstract}

Key words: Road tax; Externality; Tax rate; Czech Republic.

JEL classification: $\mathrm{H} 21, \mathrm{H} 23$.

\section{Introduction}

The transport sector is one of the important parts of each economic system. Besides positive effects, it also generates external costs transferred to other entities, or social costs resulting from negative externalities. The aim of institutional, professional and academic efforts is to find a compromise solution and an application of a suitable fiscal instrument addressing the need to reduce external costs and optimise the use of vehicles.

The road tax in the Czech Republic is included into the category of property taxes, although the OECD classification considers it a tax on the use of goods and services (OECD, 2017). Accordingly, specialised literature does not always regard the road tax as a typical property tax. Despite these aspects concerning the road tax classification, it has been included into property taxes due to the use of a similar taxation methodology. However, under the category of road tax, we would not find such concepts as environmental tax, tax on harmful effects, or tax on external costs. This fact suggests something about the difficulties inherent in the assessment of the analysed road tax.

Petr David; Mendel University in Brno, Faculty of Business and Economics, Department of Accounting and Taxes, Zemedelska 1, 61300 Brno, Czech Republic, <david@mendelu.cz>.

The article is processed as an output of a research project Fiscal quantification of environmental costs of truck traffic in the Czech Republic registered by TAČR ÉTA under the registration number TL01000308. 
The question is whether the nature of the Czech road tax corresponds to environmental tax on externalities or at least to the second best tax based on the consideration of substitute parameters of externalities. The goal of the research is to find out whether the current form of the road tax base and road tax rates can be seen as a tax which directly or indirectly considers external costs of transport. In case we ascertain that the situation is not corresponding to the tax on externalities, we shall formulate a simple general solution, necessary for the remedy of the status quo.

\section{Theoretical Background of Environmental Taxation of Externalities}

Economic and social sciences have always dealt with efforts to incorporate externalities into the market processes. A significant element in the implementation of these efforts is the first best fiscal instrument - the pure Pigovian tax as an entirely corrective tax. Pigou (1920) formulated the solution in the form of a tax which corresponds to the marginal social damage. Such a tax internalises the external cost of a producer's activity into his/her private costs.

The Pigovian tax is a pure corrective tax and its intention is to achieve an efficient level of emissions. Parry, Norregaard and Heine (2012) stress that Pigou-based environmental taxes show a lot of imperfections, if seen from today's perspective. A rather simple first best approach towards the internalisation of external costs is implemented under ideal conditions, where economists do not take into consideration the distortions produced by the implementation of a new corrective tax. In this context, Sandmo (1975) stresses that the enactment of environmental tax should be done within the framework of the already existing system of taxation.

Many scholars, e.g. Buchanan and Stubblebine (1962), Meade (1952), Coase (1960), Sandmo (1975), and others have dealt with the adjustment, construction and parameters of Pigovian taxes. Sandmo (1975) believes that Pigovian taxes can be useful if inserted into a more comprehensive system of indirect taxation.

The secondbest fiscal instrument, often referred to as Pigovian-plus-Ramsey tax (Ramsey, 1927) relies on the idea that environmental taxes should not only differ according to the social costs levels but also to the elasticity of demand. The validity of the opinion is currently confirmed by Bruvoll (2009).

There are also multi-purpose types of Pigovian taxes referred to as environmental taxes, which were formulated and examined by Goulder $(1995,2000)$ or Fullerton and Metcalf (1997). The work and results of the mentioned authors suggest that social costs do not affect just third parties, but also the pollutant agent bears its share of social costs. In an open, dynamic economy where demand and supply are 
highly related and react on reciprocal signals, taxes on externalities should be designed and incorporated into a strongly interrelated economic system.

The level of knowledge is sufficient regarding at least certain external costs of transport. Therefore they should be included in the taxation of vehicle operation in the Czech Republic, which is in line with recommendation by Leicester (2005), Nordhaus (2006), Stern et al. (2006), Parry, Walls and Harrington (2007), Sallee (2011), Johnson, Leicester and Stoye (2013), but also in accordance with the institutional goals of the European Union ensuing e.g. from the White Paper (European Commission, 2011), Decision 2013/162/EU (European Commission, 2013), Regulation (EU) 691/2011 (European Parliament and Council of the European Union, 2011) or Council Decision (EU) 2015/1339/EU (Council of the European Union, 2015). This is also in line with the United Nations' goals expressed in the United Nations Framework Convention on Climate Change (United Nations, 1992) or Kyoto Protocol to the United Nations Framework Convention on Climate Change (United Nations, 1997) and closely corresponds with the goals formulated by OECD (2011).

External costs of transport are mainly generated through local air and soil pollution, global air pollution, traffic congestions and accidents, exposure to noise and the need for infrastructure maintenance. The main items of local pollution are particulate matter (PM), nitrogen oxides (NOX), sulphur dioxide (SO2) and volatile organic compounds (VOCs), which cause negative impacts on human health, deterioration of buildings and decline in agricultural and forestry yields. Global air pollution is mainly caused by carbon dioxide (CO2), methane $(\mathrm{CH} 4)$ and nitrous oxide (N2O), which account for long-term irreversible global climate change with material consequences.

The definition of the basic differences between first and second best environmental taxation was provided by Kampas and Horan (2016). The first best tax must be easily quantifiable. It must be collected in a simple and economic way without affecting the consumers' welfare. Its receipt should not be additional revenue of public budgets, but only a transfer of funds to entities affected by the given externality. However, environmental taxes in synergy with other taxes create distortions. Although they need not generate high administrative costs, the process of their negotiation and approval as well as introduction seems very demanding and costly. The role of the current environmental taxes in modern Czech and European practice is relatively insignificant and external costs are, in most cases, addressed indirectly through substitute parameters with no feedback regarding the entities affected by externalities.

Cuervo and Ghandi (1998) note that it is costly and even impossible to determine the exact social costs of environmental externalities. The situation then has to be 
resolved through the definition of a tolerable level of environmental pollution. The second best fiscal instrument in the form of road tax based on substitute parameters of environmental pollution may lead to the achievement of pre-defined environmental goals.

The alternative to the first best taxation is therefore the inclusion of emission impacts into the road tax base and rates. According to the EU Regulation No. 691/2011, the term environmental taxation also applies to a tax whose tax base is represented by a substitute unit. The following substitute parameters are used in the European Union countries: engine capacity, engine power, fuel type, consumption, EURO standard, vehicle length, noise class, weight, axles, connection type for semi-trailers and vehicle safety features (ACEA, 2018).

\section{Data and Methods}

In order to deal with the issue of incorporating the road transport externalities into the road tax, we used the analytical and synthetic approach allowing an objective and systematic description suitable for identifying the properties of individual instruments applied in the taxation of road motor vehicles with the possibility of formulating a conclusive statement unifying the findings. The work first uses deductive procedures in order to formulate specific consequences of general statements regarding the relevant laws. The inductive, generalising approach is used in final stages of the research in order to formulate generally applicable rules, which follow from the examination of the issues concerned. Thanks to the process of abstraction, only the substantial principles of the complex system of road motor vehicle taxation may be addressed, whereas there is also a need for generalisation of the most important phenomena related to the examined issues. An important part in the theoretical work is played by the logical and systematic procedure involving the introduction to the initial state of the issue, adding further facts and connections as well as explanation of rationales and opinions. The application of the above listed methods allows for achieving the pre-defined goal, acquiring the necessary knowledge and drawing conclusions about the comparison of the findings with the principles of taxation of externalities, including the determination and assessment of the road tax progressivity in the Czech Republic.

Scholarly articles and monographs of significant and renowned experts in the area of economic and social studies were identified as valuable sources for the study of the issues concerned. It is also necessary to study other material, such as national legal documents, and documents of geopolitical institutions and professional organisations. 


\section{Results}

\subsection{Assessment of conformity of the Czech road tax with environmental principles}

Road tax in the Czech Republic is regulated by the Act No. 16/1993 Coll., on Road Tax, as amended by the 21 amendments adopted as of 2018 (Czech Republic, 2017). The subject of the road tax are road motor vehicles and their trailers, which are operated and registered in the Czech Republic and used by a payer of corporate income tax or a payer of natural persons' income tax for the activity or in direct connection with the activity generating income. Road tax is levied on all trucks and trailers registered in the Czech Republic, whose maximum permitted weight exceeds 3.5t. It means that the road tax is not levied on all sources of transport external costs, i.e. on all vehicles.

Environmentally friendly vehicles are exempt from the road tax. This includes vehicles intended for the transport of passengers with the maximum permitted weight below 12t. Such vehicles are exempt from the tax in case they have electric drive, hybrid drive combining combustion engine and electric engine, in case they use compressed natural gas (CNG), liquefied petroleum gas (LPG) as fuel or if their engine is designed by the manufacturer for the combustion of automobile petrol and ethanol E85. The preferential treatment of environmentally friendly road motor vehicles is apparently the most powerful instrument in the Czech Republic that may lead to the wider use of such vehicles (David, 2018). On the other hand, the exemption is selective and fails to take into account that even the exempt vehicles generate a certain amount of external costs. Nevertheless, the applied form of benefit for environmentally friendly vehicles is the only possible with regard to the existing definition of the tax base mentioned below.

The road tax's base for passenger cars in the Czech Republic is engine capacity expressed in cubic centimetres, which does not apply to electric vehicles. There is no tax base applicable to electric cars, as they are exempt from the tax. The tax base in the form of engine capacity may be, to an extent, classified as a substitute parameter relating to air pollution on the global level. Higher engine capacity means also higher fuel consumption and thus higher production of emissions of carbon dioxide $(\mathrm{CO} 2)$, methane $(\mathrm{CH} 4)$, nitrous oxide $(\mathrm{N} 2 \mathrm{O})$, the most important agents of global air pollution. The engine capacity also determines the level of local pollution. However, it does not take into account the parameter of technical condition of the vehicle, which is a significant variable of local air pollutants, such as particulate matter (PM), nitrogen oxides (NOX), sulphur dioxide (SO2) and volatile organic compounds (VOCs). The fuel type is not taken into account either, although it plays an important part in the production of local air pollutants. The tax 
base applied at present for passenger cars does not take into account other external costs.

The tax base for all other types of vehicles subject to the road tax is represented by the maximum permitted weight (in tons) and the number of axles. The tax base for semi-trailers is the sum of maximum permitted weights per axle in tons and the number of axles. The maximum permitted weight is a theoretical value; it is not the real weight of the vehicle. The dependence of emission levels of global air pollutants on engine capacity of passenger cars has been clearly proved (David and Křápek, 2015). Despite of that, due to the downsizing of engines and various types of fuel used, the engine capacity is not an optimal indicator if compared e.g. with the indicator of the consumption of a certain type of fuel. The road tax parameters for other vehicles and semi-trailers are disputable as far as emissions are concerned. Despite this fact, suitably set tax rates can motivate to renew the fleet, if we consider the engine capacity and other items entering into the tax base as substitute parameters of emissions. The existing type of the tax base in the form of weight can be seen as a substitute parameter for the costs expended on infrastructure. The existing type of the tax base in the form of a number of axles can be considered a substitute parameter for the costs expended on the infrastructure or local air pollution remedy. The tax base presently applied on trucks and semi-trailers does not take into account other external costs.

The road tax rate depends on the identified tax base; i.e. in the case of other vehicles and semi-trailers on the number of axles and weight and in the case of cars on the engine capacity. For cars where the tax is paid by an employer, i.e. for private cars of employees used for business purposes for which the employee receives travel expenses, the tax rate can be CZK 25 per day of use of such a car or its trailer or semi-trailer. The variant is usually selected according to which is more advantageous for the taxpayer. The above mentioned daily rate does not correspond to any external costs of transport and can be seen as a regular fee for the use of a vehicle as per OECD classification (OECD, 2017). A reduction of the road tax may be asserted in cases stipulated by the law. The apparent aim of the legal regulation is to discriminate in favour of new, presumably more environmentally friendly vehicles. The reduction may be asserted since the date of the first registration of the vehicle for the following 108 months. The reduction rates are distinctly graduated; the newest vehicles are entitled to the reduction of $48 \%$ of the basic tax rate, the subsequent reduction is $40 \%$ and the last one is $25 \%$, which applies after 36 calendar months. The entitlement to the reduction begins with the calendar month of the first registration. In case the first registration takes effect abroad, the taxpayer evidences the entitlement to the tax rate reduction with a receipt or another document issued by the relevant registration office abroad, or as the case may by, in the Czech Republic, if the Czech office has the 
information about the first registration of the vehicle. In case the vehicle was registered for the first time before the end of 1989, the tax rate increases by $25 \%$. This is a feature introduced to discourage the ownership and operation of old vehicles. The important fact is the date of the first registration, either in the CR or abroad; thus it is the age of the vehicle that matters, whereas the category of the vehicle is not decisive. The intention to levy higher duties on old, and therefore less environmentally friendly, vehicles and increase the costs of their operation, which could subsequently influence the willingness to purchase new, environmentally friendly vehicles, is again apparent. However, the above mentioned measure cannot be deemed as targeted on a certain form of external costs of vehicle operation.

Tax credit in the case of the road tax is another element affecting the resulting tax liability. It can be asserted for vehicles used in combined transportation. The significance of the tax credit from the perspective of external costs does not lie in the pressure on the renewal of the car fleet or emission reduction in existing vehicles, but rather in the effort to decrease the road motor transport in favour of more environmentally friendly forms of transport, e.g. railway or waterway transport. No direct link to any parameter of external costs of the road transport can be identified here, either.

\subsection{Identification of parameters of road tax progressivity in the CR and their assessment}

At present, tax rates according to the engine capacity range from CZK 1,200 to CZK 4,200. The higher the engine capacity, the higher the tax rate applied. The tax rates are distinctly graduated and are divided to only 6 groups according to the engine capacity. If the nature of the substitute parameter of global air pollution in the form of engine capacity should correspond to the environmental tax, then each unit of the tax base should be burdened by the same amount of tax.

\section{Tab. 1 Road tax rates for passenger cars in the CR}

\begin{tabular}{cccc}
\hline Engine capacity (cc) & $\begin{array}{c}\text { Mean values within } \\
\text { a category }(\mathbf{c c})\end{array}$ & Tax rate (CZK) & Average tax rate (CZK/cc) \\
\hline up to 800 & - & 1,200 & - \\
over 800 to 1,250 & 1,025 & 1,800 & 1.76 \\
over 1,250 to 1,500 & 1,375 & 2,400 & 1.75 \\
over 1,500 to 2,000 & 1,750 & 3,000 & 1.71 \\
over 2,000 to 3,000 & 2,500 & 3,600 & 1.44 \\
over 3,000 & - & 4,200 & - \\
\hline
\end{tabular}

Source: Czech Republic (2017), authorial computation. 
If we determine the mean values for each category of engine sizes in Table 1, we can calculate the average tax rate per unit of the engine capacity for these mean values. The results show that this average tax rate applied to mean values is degressive. This means that the tax burden per unit of engine capacity decreases with the growing size of the engine. The existing road tax rates thus fail to comply with the principles of taxes on externalities and favour cars with higher engine capacities, which contravenes the environmental goals related to the road transport in the $\mathrm{CR}$.

A car with the lowest engine capacity including complete records in the Czech register of vehicles was registered in 2008. The engine capacity of this car is 544 cc. Therefore, it makes no sense to depict unit rates for lower capacities in Figure 1. Because the last grade of the road tax for passenger cars in the CR is determined for cars with engine capacity above $3,000 \mathrm{cc}$, it is clear that the rate per unit of engine capacity will decrease and converge to zero. This finding does not comply with fundamental environmental principles, either.

\section{Fig. 1 Details of road tax unit rates for passenger cars in the CR}

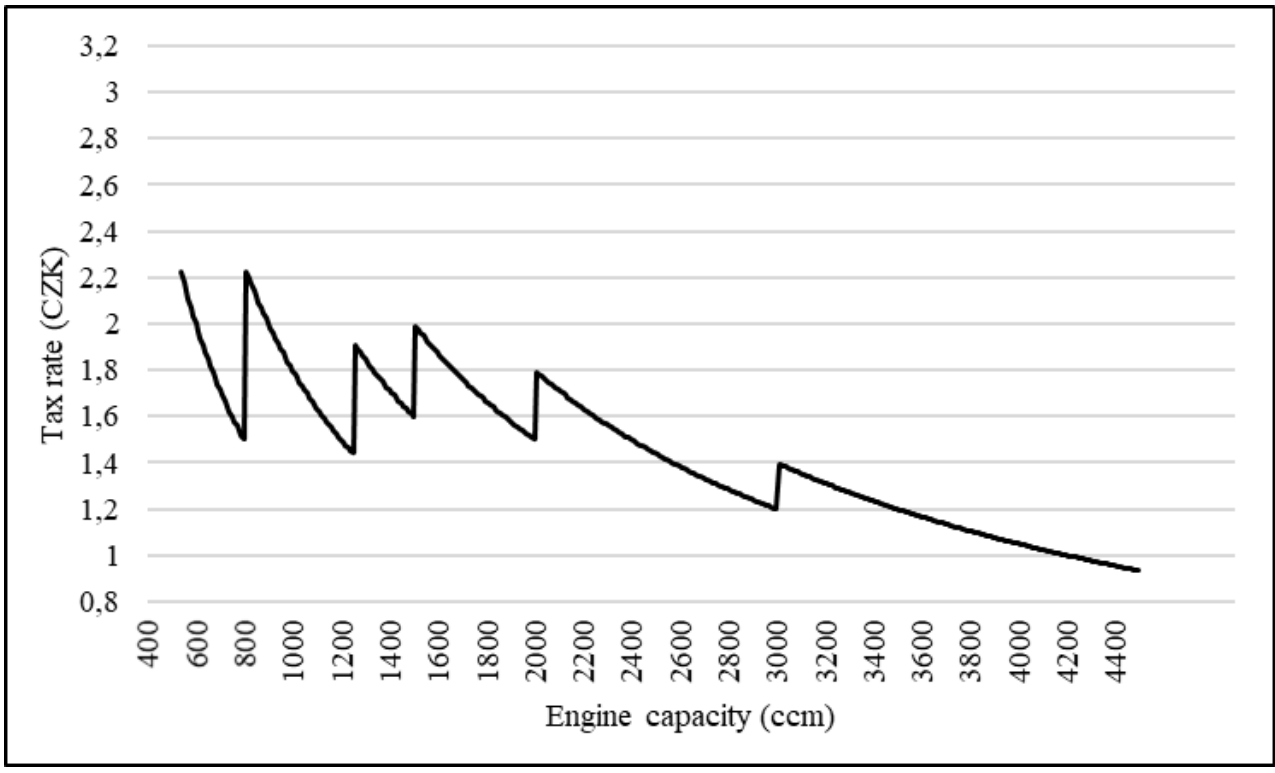

Source: Czech Republic (2017), authorial computation.

Besides the above, Figure 1 suggests that the current setting of the road tax rates for cars creates distorting grades, whose peaks do not clearly show whether vehicles with higher engine capacity are consistently taxed more, or less, than vehicles with lower engine capacity. The setting of grades causes excessive values 
of marginal tax rates within these grades and zero values of marginal tax rates in other areas of the engine capacity values. The values of upper turning points of the unit price decreases in the second turning point when compared to the first one. In the third turning point, the value of the unit rate is higher than in the second turning point. The unit rate decreases in the remaining two turning points. From the perspective of unit rates, the preferred vehicles are those with high engine capacity or with the engine capacity on the third grade of the tax rates. If the intention is the overall degressivity of unit tax rates, such intention does not comply with environmental principles. The irregularity of the third turning point is seen as an unintentional effect of the method of the determination of tax rates and their nominal amounts.

Tab. 2 Nominal rates of road tax for semi-trailers and other vehicles in the CR

\begin{tabular}{|c|c|c|c|c|c|c|c|}
\hline 1 axle $(t)$ & CZK & $2 \operatorname{axles}(t)$ & CZK & 3 axles $(t)$ & CZK & 4 and more axles (t) & CZK \\
\hline to 1 & 1,800 & to 1 & 1,800 & to 1 & 1,800 & to 18 & 8,400 \\
\hline over 1 to 2 & 2,700 & over 1 to 2 & 2,400 & over 1 to 3.5 & 2.400 & over 18 to 21 & 10,500 \\
\hline over 2 to 3.5 & 3,900 & over 2 to 3.5 & 3,600 & over 3.5 to 6 & 3,600 & over 21 to 23 & 14,100 \\
\hline over 3.5 to 5 & 5,400 & over 3.5 to 5 & 4,800 & over 6 to 8.5 & 6,000 & over 23 to 25 & 17,700 \\
\hline over 5 to 6.5 & 6,900 & over 5 to 6.5 & 6,000 & over 8.5 to 11 & 7,200 & over 25 to 27 & 22,200 \\
\hline over 6.5 to 8 & 8,400 & over 6.5 to 8 & 7.200 & over 11 to 13 & 8,400 & over 27 to 29 & 28,200 \\
\hline \multirow[t]{11}{*}{ over 8} & 9,600 & over 8 to 9.5 & 8,400 & over 13 to 15 & 10,500 & over 29 to 32 & 33,300 \\
\hline & & over 9.5 to 11 & 9,600 & over 15 to 17 & 13,200 & over 32 to 36 & 39,300 \\
\hline & & over 11 to 12 & 10,800 & over 17 to 19 & 15,900 & over 36 & 44,100 \\
\hline & & over 12 to 13 & 12,600 & over 19 to 21 & 17,400 & & \\
\hline & & over 13 to 14 & 14,700 & over 21 to 23 & 21,300 & & \\
\hline & & over 14 to 15 & 16,500 & over 23 to 26 & 27,300 & & \\
\hline & & over 15 to 18 & 23,700 & over 26 to 31 & 36,600 & & \\
\hline & & over 18 to 21 & 29,100 & over 31 to 36 & 43,500 & & \\
\hline & & over 21 to 24 & 35,100 & over 36 & 50,400 & & \\
\hline & & over 24 to 27 & 40,500 & & & & \\
\hline & & over 27 & 46,200 & & & & \\
\hline
\end{tabular}

Source: Czech Republic (2017), authorial computation.

The tax rate for semi-trailers and other vehicles depends on the number of axles and weight. The tax rates range from CZK 1,800 to 44,100. The rates are also 
based on grades, but they are more numerous than in the case of passenger cars. If the substitute parameter of external costs in the form of weight should in its nature correspond to the tax on externalities, then each unit of the given base should be burdened with the same amount of tax. If the number of axles should be the substitute parameter of air pollution, then the unit rate should grow with the growing number of axles while the weight of the vehicle remains the same. On the other hand, if the number of axles should be the substitute parameter of infrastructure damages, then the unit rate should decrease with the growing number of axles while the weight of the vehicle remains the same.

\section{Tab. 3 Average rates of road tax for semi-trailers and other vehicles in the CR}

1(t) $\quad$ CZK $\quad 2$ axles (t) $\quad$ CZK $\quad 3$ axles (t) $\quad$ CZK 4 and more axles (t) $\quad$ CZK

\begin{tabular}{|c|c|c|c|c|c|c|c|}
\hline to 1 & - & to 1 & - & to 1 & - & to 18 & - \\
\hline 1.5 & 1,800 & 1.5 & 1,600 & 2.25 & 1,067 & 19.5 & 538 \\
\hline 2.75 & 1,418 & 2.75 & 1,309 & 4.75 & 758 & 22 & 641 \\
\hline 4.25 & 1,271 & 4.25 & 1,129 & 7.25 & 828 & 24 & 738 \\
\hline 5.75 & 1,200 & 5.75 & 1,043 & 9.75 & 738 & 26 & 854 \\
\hline 7.25 & 1,159 & 7.25 & 993 & 12 & 700 & 28 & 1,007 \\
\hline \multirow[t]{11}{*}{ over 8} & - & 8.75 & 960 & 14 & 750 & 30.5 & 1,092 \\
\hline & & 10.25 & 937 & 16 & 825 & 34 & 1,156 \\
\hline & & 11.5 & 939 & 18 & 883 & over 36 & - \\
\hline & & 12.5 & 1,008 & 20 & 870 & & \\
\hline & & 13.5 & 1,089 & 22 & 968 & & \\
\hline & & 14.5 & 1,138 & 24.5 & 1,114 & & \\
\hline & & 16.5 & 1,436 & 28.5 & 1,284 & & \\
\hline & & 19.5 & 1,492 & 33.5 & 1,299 & & \\
\hline & & 22.5 & 1,560 & over 36 & - & & \\
\hline & & 25.5 & 1,588 & & & & \\
\hline & & over 27 & - & & & & \\
\hline
\end{tabular}

Source: Czech Republic (2017), authorial computation.

The grades of road tax rates for semi-trailers and other vehicles are not uniform for various numbers of axles. The grades differ by 1 to 5 tons. It is apparent that the number of grades differs for vehicles with various numbers of axles. Different values on the first and the last grade of rates for individual numbers of axles mean that a higher number of axles is expected for vehicles with higher weight. One 
does not consider a semi-trailer with one axle and a weight of $20 \mathrm{t}$, or a vehicle with four axles and a weight of $1 \mathrm{t}$.

In nominal rates (e.g. if one compares the 2nd grade for vehicles with 1 and 2 axles, or the last grade for vehicles with 3 and $4+$ axles) it is clear that the tax burden decreases with the growing number of axles while the weight of the vehicle remains the same. Thus, the tax system prefers lower damages to infrastructure over local emissions of PM, generated by the abrasion of road and tires.

There is no apparent progression or degression in relation to the vehicle weight in the context of average road tax rates for semi-trailers and other vehicles calculated in Table 3. The unit rate is degressive in the entire course of mean values of the individual categories. Degressivity was also identified in unit rates applicable to the mean values of the individual categories for vehicles with 2 axles, with the exception of the mean value of the category 18 to $21 \mathrm{t}$, where progression is apparent. In vehicles with 3 axles, degression of unit rate applicable to the mean values of the individual weight categories was identified with the exception of mean values of the category 6 to $8.5 \mathrm{t}, 13$ to $15 \mathrm{t}$ and all the other categories with mean weight over $24.5 \mathrm{t}$. Unit rates for the mean values of weight categories of vehicles with 4 and more axles are always progressive in relation to the weight. Degression of unit rates is apparent with the growing number of axles (until 4) for all categories with the same mean weight.

The above findings suggest that the existing road tax rates for semi-trailers and other vehicles do not conform to the principles of environmental tax and they allow preferential treatment of the vehicles with higher weight in most weight categories. This clearly contradicts environmental goals. The degression of rates corresponds to the goal of reduction of damage to infrastructure through the preference of more axles while the weight is the same. However, this contravenes the environmental goal of reduction of local pollution caused by PM from the abrasion of road and tires.

A van with the lowest weight was registered in the CR in 1971. Its weight is 540 $\mathrm{kg}$. Therefore, it has no sense to consider lower weights in Figure 2. The lightest vehicle from the category of heavy goods vehicles with two axles is a vehicle weighing $1,800 \mathrm{~kg}$ registered as early as in 1953 . The heaviest truck was registered in the CR in 2013 and its weight is $73,914 \mathrm{~kg}$. We did not consider this extreme in Figure 2; it would cause the loss of substantial details. The series ends with 40 t, which is by $4 \mathrm{t}$ more than the last level of road tax rates for vehicles with 3 and 4 axles. Nevertheless, we should stress that the average rate per $\mathrm{kg}$ of weight in a vehicle of $73,914 \mathrm{~kg}$ is as low as CZK 0.60 .

Because the last grades for different numbers of axles for semi-trailers and other vehicles in the CR are determined for vehicles with weight above $8 \mathrm{t}, 27 \mathrm{t}$ and $36 \mathrm{t}$, 
it is clear that beginning with these values, the rate per unit of weight will decrease and converge to zero. This finding does not correspond with fundamental principles of incorporation of transport externalities into the road tax.

Fig. 2 Average rates of road tax for semi-trailers and other vehicles in the CR

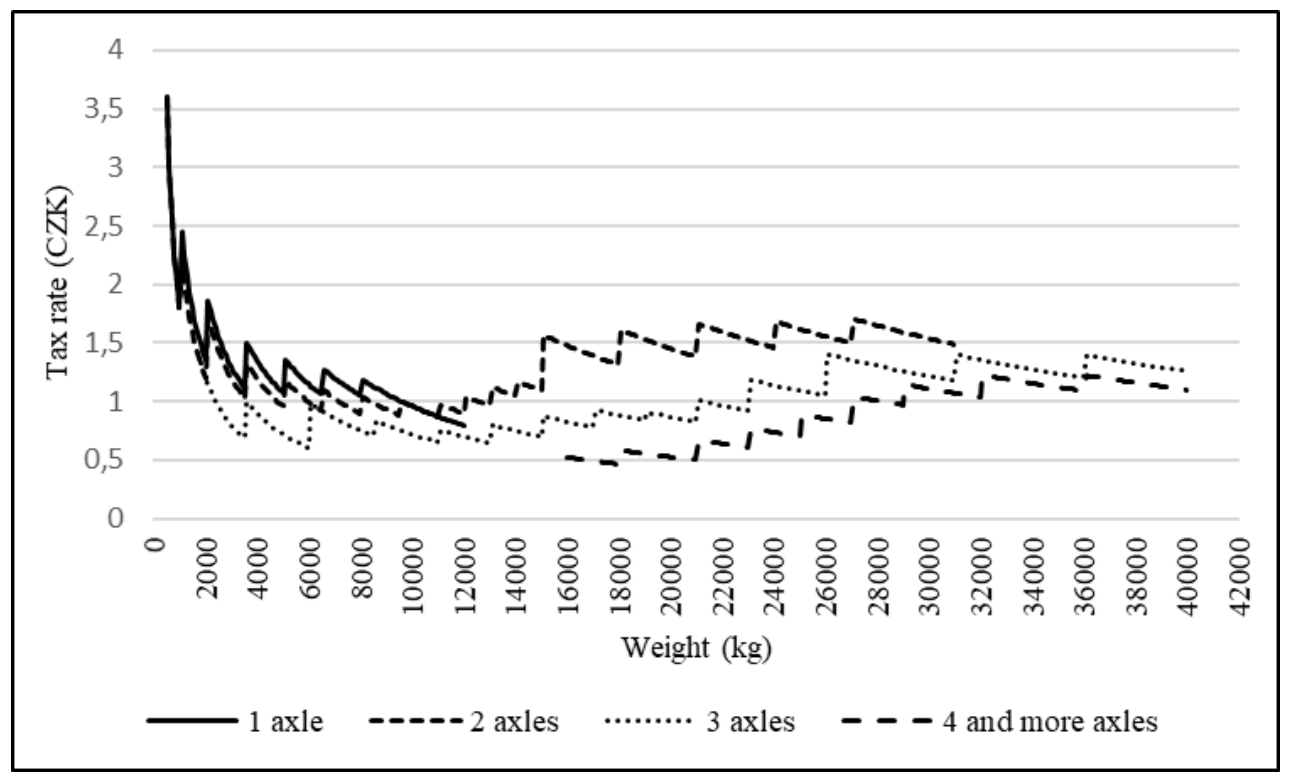

Source: Czech Republic (2017), authorial computation.

It is apparent in Figure 2 that the determination of road tax rates for semi-trailers and other vehicles, as the case is with passenger cars, creates distorting grades, whose peaks again do not clearly show whether heavier vehicles are consistently taxed more, or less, than lighter vehicles. The setting of grades causes excessive values of marginal tax rates within these grades and zero values of marginal tax rates in the other areas of values related to weight.

The graduated unit rate is degressive for vehicles with one axle. On the contrary, the unit rate is progressive for vehicles with 4 and more axles. In vehicles with 2 and 3 axles, the unit rate decreases and subsequently rises. The turning point in 2axle vehicles is in the category of 12 to $13 \mathrm{t}$ and in 3-axle vehicles in the category of 13 to $15 \mathrm{t}$. The degression in the category of 19 to $21 \mathrm{t}$ in 3 -axle vehicles is inconsistent with the above mentioned regularity. The reason behind definitely cannot be found in environmental principles.

We have mentioned the degression of unit rates with the growing number of axles (until 4), which is also testified by the curves in Figure 2. Beginning with 4 axles, 
the unit rates are proportionate in case the weight of the vehicles is the same. This means that the tax system prefers the goal of reducing the damages to infrastructure over the goal of reducing local pollution with PM generated by the abrasion of road and tires. The only exception is the situation concerning vehicles with more than 4 axles, which either favours infrastructure or local air quality.

\section{Discussion and Conclusion}

The Czech road tax base considers the engine capacity for passenger cars and the weight and number of axles for semi-trailers and other vehicles. The tax base does not include concrete indicators of external costs generated by road transport, i.e. local air and soil pollution, global air pollution, traffic congestions and accidents, exposure to noise and damage to infrastructure. The existing tax base elements can be used as substitute parameters of certain road transport externalities, which corresponds to the second best approach, mentioned and preferred by many authors, for instance Kampas and Horan (2016), Cuervo and Ghandi (1998), and others. Although the relation of emission values with the engine capacity has been proved (David a Kř́ápek, 2015), it must be admitted that this is not an optimal substitute parameter.

However, for the elements in the road tax base to be considered as substitute parameters for certain road transport externalities, the rates of this tax must be proportionate. It is also possible to consider the progression of the rates in order to create larger pressure on the generation of lesser externalities. Such progression must be flexible and not based on grades, so that distortion is prevented. It follows from ACEA (2018) that flexible rates apply in 7 EU countries. The practice in these few countries shows that the use of flexible rates is not difficult. The problem is that road tax as revenue of the state budget is on the margin of public interest. In Europe, it would not be feasible that for instance income taxes would be subject to rates based on grades, which cause distortion as has been proved by Hagopian (2011). Using the current tax bases and suitably set rates, the road tax in the CR can turn into an environmental tax and through substitute parameters take into account global air pollution from cars and general air pollution and infrastructure damage from semi-trailers and other vehicles.

Unfortunately, the Czech road tax rates for passenger cars are set as markedly graduated and from the overall perspective highly degressively. Thus, the road tax levied in the Czech Republic cannot be classified as a tax on externalities with the environmental nature.

The same applies to semi-trailers and other vehicles. From the perspective of weight, the sense and intent of the tax rate are rather incomprehensible. Lowerweight vehicles are subject to degressive rates, higher-weight vehicles are imposed 
progressive rates and for heaviest vehicles, the rate is degressive again. There is no apparent link of the tax to transport externalities, and therefore the Czech road tax levied on semi-trailers and other vehicles cannot be seen as a tax with environmental nature. As far as the number of axles is concerned, the road tax rate is degressive. It may be referred to as a tax considering the external cost of transport in the form of infrastructure damages. However, this means that the tax does not take into account local air pollution, and is not an environmental tax.

So that the road tax in the Czech Republic may comply with the principles of tax considering the externalities of road transport, it would be necessary to implement specific external cost indicators into the tax base, in line with the recommendation of Sallee (2011), Johnson, Leicester and Stoye (2013) and other authors, together with institutional goals of the European Union, United Nations and OECD. Such a change would be rather radical; it must be admitted that not all items of transport external costs can be presently measured, and if so, that such measurements are taking place. Considering this fact, an effective solution seems to maintain the existing tax bases and adjust the rates so that they are based on units, they are proportionate and as the case may be, with flexible progression related to direct or inverse proportion of the substitute parameter and the externality it represents.

\section{References}

ACEA, 2018. Acea Tax Guide 2018. Available from: <acea.be/uploads/news_documents/ACEA_Tax_Guide_2018.pdf>. [11 January 2019].

Buchanan, J. M., Stubblebine, W.C., 1962. Externality. Economica 29, 371-384. DOI: $10.2307 / 2551386$.

Bruvoll, A., 2009. On the measurement of environmental taxes. Discussion Paper No. 599. Statistics Norway, Research Department. Available from: <ssb.no/a/publikasjoner/pdf/DP/dp599.pdf>. [16 January 2019].

Coase, R. H., 1960. The problem of social cost. Palgrave Macmillan, London. DOI: 10.1057/9780230523210_6.

Council of the European Union, 2015. Council Decision (EU) 2015/1339/EU. Available from: <eur-lex.europa.eu/eli/dec/2015/1339/oj>. [8 February 2019].

Czech Republic, 2017. Act no. 16/1993 Sb., on Road Tax, as amended.

David, P., 2018. Evaluation of Road Transport taxation in the Czech Republic in an Environmental Context. In: Business Trends 2018, University of West Bohemia. 
David, P., Kŕápek, M., 2015. Solution to the unavailability of old cars' emission values for the purpose of an environmental road tax base. Central European Review of Economic Issues 18, 121-131. Available from: $<$ dspace.vsb.cz/bitstream/handle/10084/111772/VOL18NUM03PAP02_1.pdf?seq uence $=1>$. [2 June 2019].

European Commission, 2013. Commission Decision 2013/162/EU. Available from: <eur-lex.europa.eu/eli/dec/2013/162(1)/oj>. [10 February 2019].

European Commission, 2011. White Paper. Roadmap to a Single European Transport Area - Towards a competitive and resource efficient transport system. Available from: <eur-lex.europa.eu/legal-content/EN/TXT/?qid=1546425457577 \&uri=CELEX:52011DC0144>. [15 February 2019].

European Parliament and Council of the European Union, 2011. Regulation (EU) 691/2011. Available from: <eur-lex.europa.eu/eli/reg/2011/691/oj>. [9 February 2019].

Fullerton, D., Metcalf, G. E., 1997. Environmental taxes and the double-dividend hypothesis: Did you really expect something for nothing? NBER Working Paper 6199, National Bureau of Economic Research. Available from: <ase.tufts.edu/economics/papers/9706.pdf>. [18 January 2019].

Gandhi, V. P., Cuervo, J., 1998. Carbon Taxes-Their Macroeconomic Effects and Prospects for Global Adoption - a Survey of the Literature. IMF Working Paper WP/98/73. International Monetary Fund. Available from: <imf.org/en/Publications/WP/Issues/2016/12/30/Carbon-Taxes-TheirMacroeconomic-Effects-and-Prospects-for-Global-Adoption-A-Survey-of-the2601>. [14 January 2019].

Goulder, L. H., 1995. Environmental taxation and the double dividend: a reader's guide. International tax and public finance 2, 157-183. DOI: 10.1007/bf00877495.

Goulder, L. H., 2000. Economic Impacts of Environmental Policies. NBER Reporter. National Bureau of Economic Research. Available from: <nber.org/reporter/spring00/goulder.html>. [10 January 2019].

Hagopian, K., 2011. The inequity of the progressive income tax. Policy Review 166, 3-17.

Johnson, P., Leicester, A., Stoye, G., 2013. Fuel for Thought: The what, why and how of motoring taxation. Institute for Fiscal Studies for the RAC Foundation, London.

Meade, J. E., 1952. External economies and diseconomies in a competitive situation. The Economic Journal 62, 54-67. DOI: 10.2307/2227173. 
Kampas, A., Horan, R., 2016. Second-best pollution taxes: revisited and revised. Environmental Economics and Policy Studies 18, 577-597. DOI: 10.1007/s10018015-0124-3.

Leicester, A., 2005. Fuel taxation. Briefing Note No. 55. The Institute for Fiscal Studies. Available from: <ifs.org.uk/bns/bn55.pdf>. [17 January 2019].

Nordhaus, W. D., 2006. The "Stern review" on the economics of climate change. NBER Working Paper 12741. National bureau of economic research. Available from: <nber.org/papers/w12741.pdf>. [27 January 2019].

OECD, 2011. Environmental Taxation. OECD Publications. Available from: <oecd.org/env/tools-evaluation/48164926.pdf>. [13 January 2019].

OECD, 2017. Revenue Statistics. Available from: <oecd.org/tax/tax-policy/oecdclassification-taxes-interpretative-guide.pdf>. [2 March 2019].

United Nations, 1992. United Nations Framework Convention on Climate Change. Available from: <mzp.cz/C1257458002F0DC7/cz/ramcova_umluva_osn_ zmena_klimatu/\$FILE/OMV-anglicky_umluva-20081120.pdf>. [1 March 2019].

United Nations, 1997. Kyoto Protocol to the United Nations Framework Convention on Climate Change. Available from: <mzp.cz/C1257458002F0DC7/cz/kjotsky_protokol/\$FILE/OMVanglicky_protokol-20081120.pdf>. [26 February 2019].

Parry, I. W., Norregaard, J., Heine, D., 2012. Environmental tax reform: principles from theory and practice. Annu. Rev. Resour. Econ. 4, 101-125. DOI: 10.1146/annurev-resource-110811-114509.

Parry, I. W., Walls, M., Harrington, W., 2007. Automobile externalities and policies. Journal of economic literature 45, 373-399. DOI: 10.1257/jel.45.2.373.

Pigou, A. C., 1920. The economics of welfare. McMillan \& Co., London.

Ramsey, F. P., 1927. A Contribution to the Theory of Taxation. The Economic Journal 37, 47-61. DOI: 10.2307/2222721.

Sallee, J. M., 2011. The taxation of fuel economy. Tax Policy and the Economy 25, 1-38. DOI: 10.1086/658379.

Sandmo, A., 1975. Optimal taxation in the presence of externalities. The Swedish Journal of Economics 77, 86-98. DOI: 10.2307/3439329.

Stern, N., Peters, S., Bakhshi, V., Bowen, A., Cameron, C., Catovsky, S., Crane, D., Cruickshank, S., Dietz, S., Edmonson, N., Garbett, S.L., Hamid, L., Hoffman, G., Ingram, D., Jones, B., Patmore, N., Radcliffe, H., Sathiyarajah, R., Stock, M., 
European Financial and Accounting Journal, 2019, vol.14, no. 1, pp. 47-64.

Taylor, C., Vernon, T., Wanjie, H., Zenghelis, D., 2006. Stern Review: The economics of climate change. Cambridge University Press, Cambridge 
